\title{
Update on the Treatment of Venous Thromboembolism
}

\author{
Sam Schulman, MD, $\mathrm{PhD}^{1}$ \\ ${ }^{1}$ Department of Medicine, McMaster University and Thrombosis and \\ Atherosclerosis Research Institute, Hamilton, Ontario, Canada \\ Address for correspondence Sam Schulman, MD, PhD, Thrombosis \\ Service, HHS-General Hospital, 237 Barton Street East, Hamilton, \\ Ontario L8L 2X2, Canada (e-mail: schulms@mcmaster.ca).
}

Semin Thromb Hemost 2016;42:891-898.

\begin{abstract}
During the past 7 years, results from phase III trials comparing nonvitamin antagonist $\mathrm{K}$ oral anticoagulants (NOACs) with vitamin $\mathrm{K}$ antagonists (VKAs) or with placebo, including 34,900 patients, have been published. Recent guidelines have been updated and now suggest treatment with NOACs rather than with VKA. Other updates in the guidelines concern the initial thrombolytic treatment for selected patients with deep vein thrombosis or pulmonary embolism as well as the possibility of withholding anticoagulation for minimal venous thromboembolism. The optimal duration of anticoagulation after an unprovoked event is still debatable, depending on values and

Keywords

- venous thromboembolism

- thrombolysis

- anticoagulation

- clinical prediction rules preferences assigned to recurrent thromboembolism versus bleeding complications. The choice is essentially between a short duration of 3 or perhaps 6 months for extensive thromboembolism and indefinite duration. Several clinical prediction rules have been developed to aid in this choice but they all address only the risk of recurrent thrombosis without weighing in the risk of bleeding. This review provides an update on recent systematic reviews, meta-analyses, and guidelines on the treatment of venous thromboembolism.
\end{abstract}

The treatment of venous thromboembolism (VTE) has evolved in several steps. Until eight decades ago the standard treatment consisted of immobilization for several weeks with an elevation of the leg and sometimes wet and hot bandages. Subsequent discoveries changed treatment to pharmacological inhibition of plasma coagulation with an intravenous infusion with heparin followed by a vitamin $\mathrm{K}$ antagonist (VKA) and still in many countries with immobilization for a week. The next step was taken two decades ago, moving on to low-molecular-weight heparin (LMWH) injected subcutaneously followed by VKA and a progressive transition to outpatient management of the patients, mainly of those with deep vein thrombosis (DVT). Today we are seeing an evolution to the nonvitamin $\mathrm{K}$ antagonist oral anticoagulants (NOACs), which can be started without initial parenteral treatment and do not require routine coagulation monitoring.

In this review, the current management of VTE will be discussed with reference to available evidence and the most recent treatment guidelines. The treatment of pediatric VTE will not be discussed due to the paucity of evidence. Catheterdirected thrombolysis is mainly reviewed in another article in this issue of Seminars in Thrombosis and Hemostasis, and similarly, the topics of management of pulmonary embolism (PE) by the emergency team, pulmonary infarction, and postthrombotic syndrome are discussed in other articles and therefore only briefly mentioned here. Finally, DVT in unusual locations (arm, splanchnic, renal, ovarian, retinal, and cerebral veins) is not included in this review. Thrombophlebitis is a term that should be reserved for an inflammatory thrombotic phenomenon in the superficial veins and thus not part of the DVT entity.

\section{Initial Treatment Stratification}

Patients with suspected PE will be evaluated in the emergency department or, in case they are already hospitalized, on the ward. For the outpatients, a decision has to be made whether to perform imaging, typically with computed tomography of
Issue Theme Recent Advances in Thrombosis and Hemostasis - Part I; Guest Editors: Sam Schulman, MD, PhD, and Md. Shahidul Islam, MD, PhD.
Copyright $\odot 2016$ by Thieme Medical Publishers, Inc., 333 Seventh Avenue, New York, NY 10001, USA. Tel: +1(212) 584-4662.
DOI http://dx.doi.org/ 10.1055/s-0036-1592305. ISSN 0094-6176. 
the pulmonary arteries (CTPA), or not. The objective of minimizing the need for CTPA is to reduce patient exposure to radiation, costs, and time for assessment. Since clinical diagnosis alone has low sensitivity and specificity it is combined, using a clinical prediction rule such as the Wells score ${ }^{1}$ or the Geneva score, ${ }^{2}$ in combination with a biomarker that most often is the fibrin degradation product D-dimer. A recent systematic review, including six prospective studies using Wells score and D-dimer demonstrated that imaging diagnosis could be avoided in $28 \%$ of the patients. ${ }^{3}$ When the D-dimer result was age-adjusted so that the cutoff instead of $500 \mathrm{mg} / \mathrm{L}$ was (age $\times 10 \mathrm{mg} / \mathrm{L}$ ) for patients $>50$ years of age, the proportion with avoided imaging increased, although mainly among elderly outpatients. The proportion of patients with suspected PE that typically ends up with a verified diagnosis is only 10 to $20 \%$ and this strategy is therefore recommended.

Once the diagnosis has been made, the next decision for the outpatients is whether they need to be admitted to the hospital. The objective is to virtually eliminate the risk of fatal PE in the outpatient setting after this assessment. Again, clinical prediction rules are available for separating out the low-risk population, either with the Pulmonary Embolism Severity Index in the original ${ }^{4}$ or a simplified version, ${ }^{5}$ the Hestia rule, ${ }^{6}$ the criteria from recommended by the European Society of Cardiology ${ }^{7}$ or the Bova score. ${ }^{8}$

\section{Thrombolytic Therapy}

\section{Thrombolysis for Pulmonary Embolism}

Approximately 5\% of the patients with PE are hemodynamically unstable ${ }^{9}$ and require emergent diagnosis and treatment. A systolic blood pressure below $90 \mathrm{~mm} \mathrm{Hg}$ should be taken as a strong indication of this critical subgroup, which without proper management has a mortality of $58 \% .^{9,10}$ If immediate diagnosis with CTPA is not available or the patient is too unstable to be transported, bedside echocardiogram should be performed to confirm right ventricular overload. ${ }^{11}$ Hemodynamically unstable patients with PE will have a lower risk of the fatal outcome if treated with thrombolysis. The most recent version of the American College of Chest Physician (ACCP) clinical practice guidelines suggests systemically administered thrombolytic therapy (grade $2 \mathrm{~B}$ ), provided that the bleeding risk is not high. ${ }^{12}$ Two recent meta-analyses showed that thrombolytic therapy for PE reduces mortality by 41 to $43 \%$, but this reduction is not statistically significant for patients with PE and stable hemodynamics. ${ }^{13,14}$ Thrombolysis also reduces recurrences by $50 \%$, but there is a significant increase in the risk of major hemorrhage (2.7-2.9-fold) and of intracranial hemorrhage (3.2-6.8-fold). ${ }^{13,14}$

These drawbacks were clearly reflected in the hitherto largest trial in PE with thrombolysis in normotensive patients with the combination of right ventricular dysfunction and biomarkers showing myocardial injury (troponin I or troponin T) ${ }^{15}$ In the Pulmonary Embolism Thrombolysis (PEITHO) trial, 1,006 patients were randomized to tenecteplase or placebo and all received heparin. The most important outcomes are shown in -Table 1.

The conclusion should be to consider thrombolysis seriously for patients with hemodynamically unstable PE, but to be used with a clear restriction for those who have right ventricle strain but are stable. Unfortunately, the studies have not provided guidance as to which subsets would have the best risk-benefit ratio among the latter group. Young patients are less likely to suffer major bleeding, but might also be more able than the elderly to overcome the right ventricle strain and vice versa.

\section{Thrombolysis for DVT}

Three randomized trials on catheter-directed thrombolysis of DVT have been published, ${ }^{16-18}$ one of which also included mechanical disruption of the thrombus with or without thrombectomy, balloon venoplasty, or stenting. ${ }^{18}$ They all showed positive results regarding vein patency and when long-term follow-up was done ${ }^{17,18}$ also for reduction of postthrombotic syndrome. In a meta-analysis, which also included three nonrandomized studies, the efficacy benefit was confirmed but there was an increase in major bleeding (-Table 2)..$^{19}$ Thus, reduction of the postthrombotic syndrome comes at a cost of a doubling of the risk of major bleeding during the initial treatment and catheter-directed thrombolysis should currently be reserved for carefully selected cases with severe symptoms of thrombosis and a low risk of bleeding.

\section{Initial Anticoagulant Treatment}

The vast majority of patients should be treated with anticoagulants without initial thrombolysis. The standard treatment until recently has been with LMWH for at least 5 days and overlapping with a VKA until the international normalized ratio has reached the therapeutic level (2.0-3.0). The VKA should be started simultaneously with heparin rather than

Table 1 Main outcomes in the PEITHO trial ${ }^{15}$

\begin{tabular}{|l|l|l|l|l|}
\hline Outcome & Tenecteplase $(N=506)$ & Placebo $(N=498)$ & $\begin{array}{l}\text { Odds ratio } \\
(95 \% \mathrm{Cl})\end{array}$ & $p$ Value \\
\hline All-cause mortality & $6(1.2 \%)$ & $9(1.8 \%)$ & $0.65(0.23-1.85)$ & 0.42 \\
\hline Hemodynamic decompensation & $8(1.6 \%)$ & $25(5.0 \%)$ & $0.30(0.14-0.68)$ & 0.002 \\
\hline Major extracranial bleeding & $32(6.3 \%)$ & $6(1.2 \%)$ & $5.55(2.3-13.4)$ & $<0.001$ \\
\hline Stroke $^{\text {a }}$ & $12(2.4 \%)$ & $1(0.2 \%)$ & $12.1(1.6-93.4)$ & 0.001 \\
\hline
\end{tabular}

Abbreviations: $\mathrm{Cl}$, confidence interval; PEITHO, pulmonary embolism thrombolysis.

${ }^{a}$ Two of the strokes, both in the tenecteplase group, were ischemic and the remainder were hemorrhagic. 
Table 2 Results of meta-analysis of catheter-directed thrombolysis for deep vein thrombosis ${ }^{19}$

\begin{tabular}{|l|l|l|}
\hline Outcome & Odds ratio & $95 \% \mathrm{Cl}$ \\
\hline Complete lysis within 30 d & 91 & $19.3-429$ \\
\hline Patency at 6 mo & 5.77 & $1.99-16.7$ \\
\hline $\begin{array}{l}\text { Reduced postthrombotic } \\
\text { syndrome }\end{array}$ & 0.4 & $0.19-0.96$ \\
\hline Venous obstruction & 0.20 & $0.09-0.44$ \\
\hline Major bleeding & 2.0 & $1.62-2.62$ \\
\hline
\end{tabular}

Abbreviation: $\mathrm{Cl}$, confidence interval.

being delayed, and in a meta-analysis of five randomized trials comparing the two options early initiation was associated with fewer minor hemorrhages (relative risk: 0.65; 95\% confidence interval [CI]: 0.43-0.98) and fewer days in hospital (mean difference: 3.9 days; $95 \% \mathrm{CI}:-4.6$ to -3.3$).^{20}$

\section{Choice of Oral Anticoagulants}

Between 2009 and 2013, large phase III clinical trials comparing VKAs with NOACs for the treatment of VTE demonstrated similar efficacy but generally a lower risk of bleeding with the NOACs. ${ }^{21-26}$ A Cochrane meta-analysis of 11 randomized trials comparing NOACs with VKAs for the treatment of DVT showed reduced major bleeding also when separating the NOACs into direct thrombin inhibitors (odds ratio: 0.68; 95\% CI: 0.47-0.98) and factor Xa inhibitors (odds ratio: 0.57; 95\% CI: 0.43-0.76). ${ }^{27}$ In another Cochrane meta-analysis of five randomized trials comparing NOACs with VKAs for the treatment of $P E$, there were no significant differences regarding recurrent VTE, recurrent PE, all-cause mortality, or major bleeding. ${ }^{28}$ The most recent iteration of the clinical practice guidelines on antithrombotic therapy from the ACCP suggests to use NOACs rather than VKAs (grade $2 \mathrm{~B}$ ), and this is based on the reduced risk of bleeding and increased convenience for both patients and health care providers. ${ }^{12}$

Intracranial bleeding is also less frequent with NOACs than with warfarin in the treatment of VTE (relative risk: $0.37 ; 95 \%$ CI: $0.21-0.68$ ) and the same is true for fatal bleeding (relative risk: 0.36; 95\% CI: 0.15-0.84). ${ }^{29}$ Major gastrointestinal bleeding does not seem to be increased with NOACs for this indication (relative risk: $0.78 ; 95 \% \mathrm{CI}: 0.47-1.31$ ), ${ }^{29}$ but at least in the publications of the phase III trials with dabigatran and rivaroxaban, there was an increase of nonmajor gastrointestinal bleeds. ${ }^{22,24}$ That can be explained by the high concentration of active thrombin- or factor Xa-inhibitor in the stools $s^{30-32}$ and the increase in bleeds seems to be mainly in the distal gastrointestinal canal.

The "suggestion" rather than a "recommendation" by the ACCP guidelines to use NOACs is related to the indication-, physician specialty-, or patient drug coverage restrictions in various jurisdictions for the use of these drugs. ${ }^{12}$ Important patient groups for whom NOACs should not be prescribed for medical reasons are those with severe renal failure, with mechanical heart valves, or with the concomitant and indispensable use of drugs that are strong inhibitors or inducers of P-glycoprotein and/or CYP 3A4 (more than 50\% increase or reduction of exposure). The NOACs should also be prescribed with caution to patients with extreme body weights, for whom there are very little data from the clinical trials, and if selected then probably with measurement of the drug level.

\section{Specific Subgroups of Patients}

For patients with VTE and active cancer, the treatment during the first 3 months is still with LMWH, as suggested in the ACCP guidelines (grade $2 \mathrm{C}$ ). ${ }^{12}$ A meta-analysis showed that for the patient subset with cancer in the phase III trials with NOACs versus VKAs there was (during the initial treatment) actually improved efficacy to prevent recurrent VTE (relative risk: $0.57 ; 95 \% \mathrm{CI}: 0.36-0.91)$ and similar safety regarding major bleeding (relative risk: $0.77 ; 95 \% \mathrm{CI}: 0.44-1.33$ ). ${ }^{29}$ Whether this favorable benefit/risk profile will be maintained in comparison with LMWH remains to be seen from the current trials evaluating the question for factor Xa inhibitors versus LMWH.

In the elderly, there is always a concern for renal impairment, which is relevant for the NOACs that to a greater or lesser extent are dependent on elimination via the renal pathway. In addition, with increasing frailty and risk of falls, there is a more prominent tendency for intracranial hemorrhage among this population. A meta-analysis of the subsets with adults 75 years of age or older demonstrated that NOACs have better efficacy to reduce recurrent VTE (odds ratio: 0.45; 95\% CI: 0.27-0.77) without any increase in the risk of bleeding, as presented for patients with VTE or atrial fibrillation combined (odds ratio: 1.02 ; 95\% CI: $0.73-1.43$ ). ${ }^{33}$ For the elderly patients specifically treated on the VTE-indication there seems to be a lower risk of major bleeding with NOACs, as shown in another meta-analysis (relative risk: $0.49 ; 95 \% \mathrm{CI}$ : $0.25-0.96) .{ }^{29}$ The explanation could be that patients in the VTE trials were younger than those in the studies on atrial fibrillation and had less frequently concomitant treatment with antiplatelet agents.

In the phase III trials, patients were excluded if they had a calculated creatinine clearance of less than $30 \mathrm{~mL} / \mathrm{min}$ (less than $25 \mathrm{~mL} / \mathrm{min}$ for apixaban). Patients with a calculated creatinine clearance of 30 to $49 \mathrm{~mL} / \mathrm{min}$, typically considered as moderate renal failure, fared well in the VTE trials with similar efficacy compared with VKAs (relative risk: 0.70; 95\% CI: 0.43-1.15) and reduced risk for major bleeding (relative risk: 0.51 ; $95 \% \mathrm{CI}: 0.26-0.99) .{ }^{29}$ Specifically for dabigatran, the scenario seems to be reversed among those with moderate renal impairment, with better efficacy than with warfarin ( 0 vs. 5 recurrences) and similar safety (6 vs. 5 major bleeds), ${ }^{34}$ most likely related to the higher plasma concentration of dabigatran with reduced glomerular filtration rate.

\section{Duration of Anticoagulation}

The default duration of anticoagulation after the first VTE is 3 months. ${ }^{12}$ Treatment for a longer but limited period of 6 or 12 or 24 months will result in the same long-term risk of 
recurrent VTE in most patients. Thus, the choice is typically between a limited, short duration, and indefinite duration. The latter should be considered when the risk of recurrence is high and the risk of bleeding is relatively low.

The ACCP guidelines from 2016 recommend extended duration of anticoagulation for patients with a second event of VTE (grade 1B), and for patients with cancer (grade 1B). ${ }^{12}$ For the latter, the duration should be evaluated at least on an annual basis and when the cancer is considered cured, treatment can be discontinued. ${ }^{35}$ Furthermore, the indefinite duration is suggested for patients with a first, unprovoked VTE when the bleeding risk is low-to-moderate (grade $2 \mathrm{~B}$ ). ${ }^{12}$ Here, we obviously have a debatable situation. The risk of recurrent VTE is approximately 30 to $40 \%$ over the following decade if anticoagulation is stopped, ${ }^{36}$ levelling off at around $50 \%$ as a lifetime risk. Therefore, if we decide to treat all patients fulfilling these criteria, $50 \%$ will be treated unnecessarily but with the concomitant risk of major bleeding of 2 to $3 \%$ per year. ${ }^{37}$ Case fatality of recurrent VTE (without anticoagulation) is approximately balanced by the case fatality of major bleeds on anticoagulation, although the confidence intervals are quite large. ${ }^{38}$

\section{Additional Risk Factors for Recurrent VTE}

It has repeatedly been demonstrated that male sex is associated with an increased risk of recurrent VTE with a pooled estimate of relative risk from randomized and nonrandomized trials of 1.6 (95\% CI: $1.2-2.0) .{ }^{39}$ The male sex effect seems to be so important that additional risk stratification with D-dimer is not helpful. ${ }^{40}$ In females with the VTE provoked by hormonal treatment, which subsequently has been discontinued, the risk of recurrence is so low $(0.0 \%$; $95 \% \mathrm{CI}$ : $0.0-0.3)$ that no further risk stratification is necessary. ${ }^{40}$ However, in women with unprovoked VTE the use of D-dimer, with a normal level at the time of planned completion of treatment and then another normal level after 1 month without anticoagulation can select individuals with an acceptably low risk of recurrence $(5.4 \% \text {; } 95 \% \mathrm{CI}: 2.5-10.2)^{40}$ so that it can be suggested to them to remain off treatment.

Part of the explanation for the different risk of recurrence in men and women could be the ability to efficiently resolve the clot. In a study of 869 consecutive patients with DVT, half had residual vein thrombosis after 3 months. ${ }^{41}$ This was defined as at least $4 \mathrm{~mm}$ of incompressibility in the common femoral or popliteal vein with ultrasound. The residual thrombosis was more frequent in males (adjusted odds ratio: 1.82; 95\% CI: 1.37-2.04). Residual vein thrombosis might therefore also be helpful in the risk stratification for extended anticoagulation.

The combined predictive value of elevated D-dimer and residual vein thrombosis was explored in another study with 296 patients but here residual vein thrombosis was not associated with additional risk of recurrent VTE compared with abnormal D-dimer alone. ${ }^{42}$ In a systematic review, the presence of residual vein thrombosis did not appear to predict recurrent VTE among patients with an unprovoked index event. ${ }^{43}$ In a more recent patient-level meta-analysis of 10 prospective studies there was an independent, significant association between residual venous obstruction and risk of recurrent VTE (hazard ratio [HR]: 1.32; 95\% CI: 1.06-1.65) and even more so if the obstruction had been detected at 3 months after the first thrombosis (HR: 2.17; 95\% CI: 1.11-4.25). ${ }^{44}$

Clinical prediction rules have been constructed to attempt more efficient identification of patients at high risk of recurrent VTE. They are presented in - Table 3. For the DASH score, a receiver operating curve analysis showed that the area under the curve was better than for D-dimer alone ( $0.71 \mathrm{vs}$. 0.61). ${ }^{45}$ Unfortunately, the prediction rules might not be helpful in all populations, for example, the elderly, for whom the Updated Vienna Prediction Model was not helpful to discriminate patients at high risk. ${ }^{46}$ A systematic review of

Table 3 Clinical prediction rules for recurrence of venous thromboembolism

\begin{tabular}{|l|l|l|}
\hline Name, reference & Components & Interpretation \\
\hline Vienna 47,56 & $\begin{array}{l}\text { Male sex } \\
\text { Proximal DVT and/or PE } \\
\text { Elevated D-dimer }\end{array}$ & Nomogram with continuous model \\
\hline DASH $^{45}$ & $\begin{array}{l}\text { D-dimer } \\
\text { Age } \\
\text { Sex } \\
\text { Hormonal therapy }\end{array}$ & Score $\leq 1 \rightarrow$ annual risk 3.1\% \\
& $\begin{array}{l}\text { Postthrombotic signs } \\
\text { D-dimer } \geq 250 \mu g / L \\
\text { Men continue and HER DOO2 }\end{array}$ & \\
& Body mass index $\geq 30$ & Only for females) \\
& Age $\geq 65$ & 0 or 1 of the criteria $\rightarrow$ annual risk $<3 \%$ \\
& D-dimer after cessation \\
& Lag time & \\
\hline RVTEC & Age & Equation with continuous model \\
& Sex & \\
& VTE location & \\
\hline
\end{tabular}

Abbreviations: DVT, deep vein thrombosis; PE, pulmonary embolism; RVTEC, recurrent VTE collaborative; VTE, venous thromboembolism. 
the clinical prediction rules Vienna, ${ }^{47} \mathrm{DASH}^{45}$ and HER $\mathrm{DOO}^{48}$ noted that they all lacked external validation and multiple imputations had not been considered to handle missing data. ${ }^{49}$ The authors then used individual patient data from seven trials to test other prognostic models and then performed internal-external cross-validation, followed by a Markov patient-level simulation for cost-effectiveness. They concluded that a model including D-dimer after cessation of anticoagulation (whenever performed) together with the lag time, age, sex, and location of VTE performed strongly to predict a risk $>8 \%$ annually for recurrent VTE within 2 to 3 years with an average c-statistic of 0.69 and it appeared costeffective. $^{49}$

\section{Patients that Might Not Require Anticoagulation}

For patients with very limited extension of the VTE, there is a possibility that anticoagulant therapy causes more harm than benefit. A DVT in the veins distal to the trifurcation is small in volume but if the patient has pronounced pain and/or swelling it is difficult to justify the no-treatment option. Risk factors for thrombus extension should also be taken into account as summarized in - Table $4 .^{12} \mathrm{~A}$ recent meta-analysis of two randomized trials and six cohort studies on patients with distal DVT concluded that the methodological quality was poor so, although thrombus propagation and PE were reduced with anticoagulation, the finding was not robust. ${ }^{50}$ For patients that do not receive anticoagulant therapy, the guidelines suggest serial monitoring of the extension of the thrombus with ultrasound for 2 weeks (grade 2C). ${ }^{12}$

The second group of patients with minimal VTE is those with the PE confined to the subsegmental pulmonary arteries. These small defects seen on CTPA but often not on isotope scanning can be false-positive findings. In a systematic review of 2 randomized trials and 20 prospective cohort studies, where the rate of subsegmental PE had been reported, this rate was 4.7 and $9.4 \%$ with single- and multidetector CTPA, respectively. ${ }^{51}$ The 3-month risk of VTE after untreated subsegmental PE was 0.9 and $1.1 \%$ when single- or multidetector CTPA had been used. Based on this, it is conceivable that these minute defects are not clinically important. An important precaution is then to perform bilateral compression ultrasound and if DVT is excluded the patients is a good candidate for clinical surveillance without anticoagulation. The guidelines suggest that patients with subsegmental defects but at high risk for recurrent VTE (- Table 4) should receive anticoagulation (grade $2 \mathrm{C}$ ). ${ }^{12}$

\section{Postthrombotic Syndrome}

Symptoms and signs of postthrombotic syndrome affect at least half of the patients with a previous VTE. ${ }^{52}$ It has thus been of great interest to find therapeutic measures to reduce this occurrence, particularly for the patients that end up with more severe forms of chronic edema, pain, ulcers. Catheterdirected thrombolysis has been discussed above but this alternative demands special resources and only a small proportion of patients with acute VTE appear to be eligible, even in a trial with active recruitment. ${ }^{53}$ Compression stockings are possible to use in a majority of patients. In a large, double-blind, placebocontrolled randomized trial it was, however, shown that compression stockings for 2 years were not more effective than placebo stockings to reduce postthrombotic syndrome ${ }^{54}$ or acute leg pain. ${ }^{55}$ Compression stockings are accordingly not recommended for routine use after DVT (grade 2B). ${ }^{12}$ Elastic compression stockings may still be of benefit for patients already suffering from the postthrombotic syndrome.

\section{Conclusions}

The main novelty in the management of VTE is the introduction of NOACs in the therapeutic armament. These are attractive alternatives to VKAs due to the convenience for patients and physicians. Important quantifiable benefits are the reduction of risk for intracranial bleeding and the immediate achievement of therapeutic levels. There are, however, important patient groups for whom VKAs are still been the only or main option based on comorbidities, comedications, and affordability. Patients with the minimal thromboembolic disease, that is, distal DVT or subsegmental PE and otherwise at low risk for recurrent VTE, should be considered for clinical surveillance alone. Thrombolytic therapy is suggested for hemodynamically unstable patients but not for those with right ventricle strain and stable hemodynamics. Catheter-directed thrombolysis for DVT should not be used routinely but restricted for carefully selected patients. Elastic compression stockings for prevention of postthrombotic syndrome are no longer recommended.

Table 4 Risk factors that support anticoagulation rather than no treatment ${ }^{12}$

\begin{tabular}{|l|l|}
\hline Distal deep vein thrombosis & Subsegmental pulmonary embolism \\
\hline - Extensive thrombus (> $5 \mathrm{~cm}$ ) or present in several veins & $\begin{array}{l}\text { - Marked symptoms, not attributable to other cause } \\
\text { - Location close to proximal veins }\end{array}$ \\
$\begin{array}{l}\text { - Permanent provoking risk factor or unprovoked thrombosis } \\
\text { - Active cancer }\end{array}$ & $\begin{array}{l}\text { - Permanent provoking risk factor or unprovoked thrombosis } \\
\text { - Hospitalized patient }\end{array}$ \\
$\begin{array}{l}\text { - Hospitalized patient } \\
\text { - High D-dimer level without another apparent cause }\end{array}$ & - Previous venous thromboembolism \\
\hline
\end{tabular}




\section{Conflict of Interest}

Sam Schulman reports receiving consulting fees from Boehringer Ingelheim, Bristol-Myers-Squibb, Bayer and Daiichi-Sankyo and grant support from Boehringer Ingelheim, Baxter and Octapharma.

\section{Note}

No funding was received for writing this review article.

\section{References}

1 Wells PS, Anderson DR, Rodger M, et al. Derivation of a simple clinical model to categorize patients probability of pulmonary embolism: increasing the models utility with the SimpliRED Ddimer. Thromb Haemost 2000;83(3):416-420

2 Le Gal G, Righini M, Roy PM, et al. Prediction of pulmonary embolism in the emergency department: the revised Geneva score. Ann Intern Med 2006;144(3):165-171

3 van Es N, van der Hulle T, van Es J, et al. Wells rule and D-dimer testing to rule out pulmonary embolism: a systematic review and individual-patient data meta-analysis. Ann Intern Med 2016; 165(4):253-261

4 Aujesky D, Obrosky DS, Stone RA, et al. Derivation and validation of a prognostic model for pulmonary embolism. Am J Respir Crit Care Med 2005;172(8):1041-1046

5 Jiménez D, Aujesky D, Moores L, et al; RIETE Investigators. Simplification of the pulmonary embolism severity index for prognostication in patients with acute symptomatic pulmonary embolism. Arch Intern Med 2010;170(15):1383-1389

6 Zondag W, Vingerhoets LM, Durian MF, et al; Hestia Study Investigators. Hestia criteria can safely select patients with pulmonary embolism for outpatient treatment irrespective of right ventricular function. J Thromb Haemost 2013;11(4):686-692

7 Torbicki A, Perrier A, Konstantinides S, et al; ESC Committee for Practice Guidelines (CPG). Guidelines on the diagnosis and management of acute pulmonary embolism: the Task Force for the Diagnosis and Management of Acute Pulmonary Embolism of the European Society of Cardiology (ESC). Eur Heart J 2008;29(18): 2276-2315

8 Bova C, Sanchez O, Prandoni P, et al. Identification of intermediaterisk patients with acute symptomatic pulmonary embolism. Eur Respir J 2014;44(3):694-703

9 Kucher N, Rossi E, De Rosa M, Goldhaber SZ. Massive pulmonary embolism. Circulation 2006;113(4):577-582

10 Jerjes-Sanchez C, Ramírez-Rivera A, Arriaga-Nava R, et al; de Lourdes García M. Streptokinase and heparin versus heparin alone in massive pulmonary embolism: a randomized controlled trial. J Thromb Thrombolysis 1995;2(3):227-229

11 Agnelli G, Becattini C. Acute pulmonary embolism. N Engl J Med 2010;363(3):266-274

12 Kearon C, Akl EA, Ornelas J, et al. Antithrombotic Therapy for VTE Disease: CHEST Guideline and Expert Panel Report. Chest 2016; 149(2):315-352

13 Marti C, John G, Konstantinides S, et al. Systemic thrombolytic therapy for acute pulmonary embolism: a systematic review and meta-analysis. Eur Heart J 2015;36(10):605-614

14 Wang TF, Squizzato A, Dentali F, Ageno W. The role of thrombolytic therapy in pulmonary embolism. Blood 2015;125(14):2191-2199

15 Meyer G, Vicaut E, Danays T, et al; PEITHO Investigators. Fibrinolysis for patients with intermediate-risk pulmonary embolism. N Engl J Med 2014;370(15):1402-1411

16 Elsharawy M, Elzayat E. Early results of thrombolysis vs anticoagulation in iliofemoral venous thrombosis. A randomised clinical trial. Eur J Vasc Endovasc Surg 2002;24(3):209-214
17 Enden T, Haig Y, Kløw NE, et al; CaVenT Study Group. Long-term outcome after additional catheter-directed thrombolysis versus standard treatment for acute iliofemoral deep vein thrombosis (the CaVenT study): a randomised controlled trial. Lancet 2012; 379(9810):31-38

18 Sharifi M, Mehdipour M, Bay C, Smith G, Sharifi J. Endovenous therapy for deep venous thrombosis: the TORPEDO trial. Catheter Cardiovasc Interv 2010;76(3):316-325

19 Du GC, Zhang MC, Zhao JC. Catheter-directed thrombolysis plus anticoagulation versus anticoagulation alone in the treatment of proximal deep vein thrombosis - a meta-analysis. Vasa 2015; 44(3):195-202

20 Qayyum F, Holbrook A, Lam J, Kovacs MJ, Schulman S. Should vitamin $\mathrm{K}$ antagonist therapy be started simultaneously with parenteral anticoagulation: a meta-analysis? Blood Coagul Fibrinolysis 2012;23(8):705-713

21 Agnelli G, Buller HR, Cohen A, et al; AMPLIFY Investigators. Oral apixaban for the treatment of acute venous thromboembolism. N Engl J Med 2013;369(9):799-808

22 Bauersachs R, Berkowitz SD, Brenner B, et al; EINSTEIN Investigators. Oral rivaroxaban for symptomatic venous thromboembolism. N Engl J Med 2010;363(26):2499-2510

23 Büller HR, Prins MH, Lensin AW, et al; EINSTEIN-PE Investigators. Oral rivaroxaban for the treatment of symptomatic pulmonary embolism. N Engl J Med 2012;366(14):1287-1297

24 Schulman S, Kakkar AK, Goldhaber SZ, et al; RE-COVER II Trial Investigators. Treatment of acute venous thromboembolism with dabigatran or warfarin and pooled analysis. Circulation 2014; 129(7):764-772

25 Schulman S, Kearon C, Kakkar AK, et al; RE-COVER Study Group. Dabigatran versus warfarin in the treatment of acute venous thromboembolism. N Engl J Med 2009;361(24):2342-2352

26 Büller HR, Décousus H, Grosso MA, et al; Hokusai-VTE Investigators. Edoxaban versus warfarin for the treatment of symptomatic venous thromboembolism. N Engl J Med 2013;369(15): 1406-1415

27 Robertson L, Kesteven P, McCaslin JE. Oral direct thrombin inhibitors or oral factor Xa inhibitors for the treatment of deep vein thrombosis. Cochrane Database Syst Rev 2015;(6):CD010956

28 Robertson L, Kesteven P, McCaslin JE. Oral direct thrombin inhibitors or oral factor Xa inhibitors for the treatment of pulmonary embolism. Cochrane Database Syst Rev 2015;(12):CD010957

29 van Es N, Coppens M, Schulman S, Middeldorp S, Büller HR. Direct oral anticoagulants compared with vitamin K antagonists for acute venous thromboembolism: evidence from phase 3 trials. Blood 2014;124(12):1968-1975

30 Blech S, Ebner T, Ludwig-Schwellinger E, Stangier J, Roth W. The metabolism and disposition of the oral direct thrombin inhibitor, dabigatran, in humans. Drug Metab Dispos 2008;36(2):386-399

31 Weinz C, Schwarz T, Kubitza D, Mueck W, Lang D. Metabolism and excretion of rivaroxaban, an oral, direct factor Xa inhibitor, in rats, dogs, and humans. Drug Metab Dispos 2009;37(5):1056-1064

32 Zhang D, Frost CE, He K, et al. Investigating the enteroenteric recirculation of apixaban, a factor Xa inhibitor: administration of activated charcoal to bile duct-cannulated rats and dogs receiving an intravenous dose and use of drug transporter knockout rats. Drug Metab Dispos 2013;41(4):906-915

33 Sardar P, Chatterjee S, Chaudhari S, Lip GY. New oral anticoagulants in elderly adults: evidence from a meta-analysis of randomized trials. J Am Geriatr Soc 2014;62(5):857-864

34 Schulman S, Eriksson H, Goldhaber SZ, et al. Influence of renal function on the efficacy and safety of dabigatran versus warfarin for the treatment of acute venous thromboembolism: a pooled analysis from RE-Cover and RE-Cover II. Blood 2013;122:212

35 van der Hulle T, den Exter PL, van den Hoven P, et al. Cohort study on the management of cancer-associated venous thromboembolism aimed at the safety of stopping anticoagulant therapy in patients cured of cancer. Chest 2016;149(5):1245-1251 
36 Prandoni P, Villalta S, Bagatella P, et al. The clinical course of deepvein thrombosis. Prospective long-term follow-up of 528 symptomatic patients. Haematologica 1997;82(4):423-428

37 Lopes LC, Spencer FA, Neumann I, et al. Bleeding risk in atrial fibrillation patients taking vitamin $\mathrm{K}$ antagonists: systematic review and meta-analysis. Clin Pharmacol Ther 2013;94(3): 367-375

38 Carrier M, Le Gal G, Wells PS, Rodger MA. Systematic review: casefatality rates of recurrent venous thromboembolism and major bleeding events among patients treated for venous thromboembolism. Ann Intern Med 2010;152(9):578-589

39 McRae S, Tran H, Schulman S, Ginsberg J, Kearon C. Effect of patient's sex on risk of recurrent venous thromboembolism: a meta-analysis. Lancet 2006;368(9533):371-378

40 Kearon C, Spencer FA, O'Keeffe D, et al; D-dimer Optimal Duration Study Investigators. D-dimer testing to select patients with a first unprovoked venous thromboembolism who can stop anticoagulant therapy: a cohort study. Ann Intern Med 2015;162(1):27-34

41 Prandoni P, Lensing AW, Prins $\mathrm{MH}$, et al. The impact of residual thrombosis on the long-term outcome of patients with deep venous thrombosis treated with conventional anticoagulation. Semin Thromb Hemost 2015;41(2):133-140

42 Cosmi B, Legnani C, Iorio A, et al; PROLONG Investigators (on behalf of FCSA, Italian Federation of Anticoagulation Clinics). Residual venous obstruction, alone and in combination with $\mathrm{D}$-dimer, as a risk factor for recurrence after anticoagulation withdrawal following a first idiopathic deep vein thrombosis in the prolong study. Eur J Vasc Endovasc Surg 2010;39(3):356-365

43 Carrier M, Rodger MA, Wells PS, Righini M, LE Gal G. Residual vein obstruction to predict the risk of recurrent venous thromboembolism in patients with deep vein thrombosis: a systematic review and meta-analysis. J Thromb Haemost 2011;9(6):1119-1125

44 Donadini MP, Ageno W, Antonucci E, et al. Prognostic significance of residual venous obstruction in patients with treated unprovoked deep vein thrombosis: a patient-level meta-analysis. Thromb Haemost 2014;111(1):172-179

45 Tosetto A, Iorio A, Marcucci M, et al. Predicting disease recurrence in patients with previous unprovoked venous thromboembolism: a proposed prediction score (DASH). J Thromb Haemost 2012; 10(6):1019-1025

46 Tritschler T, Méan M, Limacher A, Rodondi N, Aujesky D. Predicting recurrence after unprovoked venous thromboembolism: prospec- tive validation of the updated Vienna Prediction Model. Blood 2015;126(16):1949-1951

47 Eichinger S, Heinze G, Jandeck LM, Kyrle PA. Risk assessment of recurrence in patients with unprovoked deep vein thrombosis or pulmonary embolism: the Vienna prediction model. Circulation 2010;121(14):1630-1636

48 Rodger MA, Kahn SR, Wells PS, et al. Identifying unprovoked thromboembolism patients at low risk for recurrence who can discontinue anticoagulant therapy. CMAJ 2008;179(5): 417-426

49 Ensor J, Riley RD, Jowett S, et al; PIT-STOP collaborative group. Prediction of risk of recurrence of venous thromboembolism following treatment for a first unprovoked venous thromboembolism: systematic review, prognostic model and clinical decision rule, and economic evaluation. Health Technol Assess 2016; 20(12):i-xxxiii, 1-190

50 De Martino RR, Wallaert JB, Rossi AP, Zbehlik AJ, Suckow B, Walsh DB. A meta-analysis of anticoagulation for calf deep venous thrombosis. J Vasc Surg 2012;56(1):228-37.e1, discussion 236237

51 Carrier M, Righini M, Wells PS, et al. Subsegmental pulmonary embolism diagnosed by computed tomography: incidence and clinical implications. A systematic review and meta-analysis of the management outcome studies. J Thromb Haemost 2010;8(8): 1716-1722

52 Schulman S, Lindmarker P, Holmström M, et al. Post-thrombotic syndrome, recurrence, and death 10 years after the first episode of venous thromboembolism treated with warfarin for 6 weeks or 6 months. J Thromb Haemost 2006;4(4):734-742

53 Schulman S. Getting intimate with the venous thrombus. J Thromb Haemost 2009;7(8):1266-1267

54 Kahn SR, Shapiro S, Wells PS, et al; SOX trial investigators. Compression stockings to prevent post-thrombotic syndrome: a randomised placebo-controlled trial. Lancet 2014;383(9920): 880-888

55 Kahn SR, Shapiro S, Ducruet T, et al. Graduated compression stockings to treat acute leg pain associated with proximal DVT. A randomised controlled trial. Thromb Haemost 2014;112(6): 1137-1141

56 Eichinger S, Heinze G, Kyrle PA. D-dimer levels over time and the risk of recurrent venous thromboembolism: an update of the Vienna prediction model. J Am Heart Assoc 2014;3(1):e000467 